\title{
Accuracy analysis of the 2014-2015 Global Shuttle Radar Topography Mission (SRTM) 1 arc-sec C-Band height model using International Global Navigation Satellite System Service (IGS) Network
}

\author{
Manas Mukul ${ }^{1}$, Vinee Srivastava ${ }^{2}$ and Malay Mukul ${ }^{2, *}$ \\ ${ }^{1}$ KIIT University, Bhubaneswar 751 024, India. \\ ${ }^{2}$ Continental Deformation Laboratory, Department of Earth Sciences, \\ Indian Institute of Technology Bombay, Mumbai 400 076, India. \\ ${ }^{*}$ Corresponding author.e-mail: malaymukul@iitb.ac.in
}

Global Shuttle Radar Topography Mission (SRTM) data products have been widely used in Earth Sciences without an estimation of their accuracy and reliability even though large outliers exist in them. The global 1 arc-sec, 30 m resolution, SRTM C-Band (C-30) data collected in February 2000 has been recently released (2014-2015) outside North America. We present the first global assessment of the vertical accuracy of C-30 data using Ground Control Points (GCPs) from the International GNSS Service (IGS) Network of high-precision static fiducial stations that define the International Terrestrial Reference Frame (ITRF). Large outliers (height error ranging from -1285 to $2306 \mathrm{~m}$ ) were present in the C-30 dataset and $14 \%$ of the data were removed to reduce the root mean square error (RMSE) of the dataset from $\sim 187$ to $10.3 \mathrm{~m}$ which is close to the SRTM goal of an absolute vertical accuracy of RMSE $\sim 10 \mathrm{~m}$. Globally, for outlier-filtered data from 287 GCPs, the error or difference between IGS and SRTM heights exhibited a non-normal distribution with a mean and standard error of $6.5 \pm 0.5 \mathrm{~m}$. Continent-wise, only Australia, North and South America complied with the SRTM goal. At stations where all the Xand C-Band SRTM data were present, the RMSE of the outlier-filtered C-30 data was $11.7 \mathrm{~m}$. However, the RMSE of outlier-included dataset where C- and X-Band data were present was $\sim 233 \mathrm{~m}$. The results suggest that the SRTM data must only be used after regional accuracy analysis and removal of outliers. If used raw, they may produce results that are statistically insignificant with RMSE in 100s of meters.

\section{Introduction}

The Shuttle Radar Topography Mission (SRTM) collected near-global data during the 11-day mission (Bamler 1999; Farr and Kobrick 2000; Werner 2001; Rabus et al. 2004) in February 2000 at a resolution of $30 \mathrm{~m}$ (1 arc-sec) using C- and X-Band antennae (Farr and Kobrick 2000). The X-Band data were available in $30 \mathrm{~m}$ resolution but with limited coverage due to the lower swath width of the X-Band antennae. The C-Band data were released globally (except the USA, where it was released at $30 \mathrm{~m}$ ) after re-sampling it to $90 \mathrm{~m}$ (3 arc-sec) resolution. However, since September 2014, the 1-arc, C-Band $30 \mathrm{~m}$ SRTM (C-30) data have been released in a phased manner outside USA. The C-30 data for North and South America and parts of Africa and Europe were released on September 23, 2014 followed by data from Australia and parts of Asia on January 2, 2015. The remaining C-30 data in

Keywords. Geodesy; error; accuracy; geo-referencing; GPS/GNSS; radar; DEM/DTM; DTED; SRTM. 
the Arabian peninsula and some parts of Europe, Africa and Asia were released on August 6, 2015. It is appropriate, therefore, to now extend the Mukul Manas et al. (2015) methodology to assess the accuracy of the global C-30 data and explore a robust strategy for using the SRTM data products. Global SRTM Digital Terrain Elevation Data (DTED) have been widely used in Earth Sciences but are typically used ignoring errors that can affect results (Wechsler 2003) even though several studies have indicated that large outliers exist in the Shuttle Radar Topography Mission (SRTM) data products (e.g., Rodriguez et al. 2005; Mouratidis et al. 2010; Kolecka and Kozak 2014). In this study we use the high-precision GCPs of the International GNSS Service (IGS) Network (Dow et al. 2009) to answer the following questions related to the accuracy of C-30 data compared to the targeted SRTM vertical accuracy of RMSE of $\sim 10 \mathrm{~m}$ (and not 16 m, e.g., Varga and Tomisla 2015) corresponding to a linear error at $90 \%$ confidence (LE90) of 16 m (Rabus et al. 2004; USGS 2005; Farr et al. 2007; JPL 2009):

1. What is the vertical accuracy of the 1-arc CBand $30 \mathrm{~m}$ resolution SRTM data using GCPs from the International GNSS Service (IGS) Network of high-precision static fiducial stations that define the International Terrestrial Reference Frame (ITRF) IGS Network?

2. How does the vertical accuracy of 1 -arc C-Band $30 \mathrm{~m}$ data compare with the accuracy of 1-arc $\mathrm{X}$-Band $30 \mathrm{~m}$ and 3 -arc C-Band $90 \mathrm{~m}$ data? Is there a marked improvement in the vertical accuracy of the 1-arc C-Band $30 \mathrm{~m}$ SRTM data over previously released datasets?

3. What is the strategy to follow while using SRTM data products? Can we really use raw SRTM products without worrying about uncertainties involved?

\section{Methodology}

This study is an extension of Mukul Manas et al.'s (2015) study carried out for the 3-arc C-Band $90 \mathrm{~m}$ resolution C-90 data (C-90) and, therefore, we have followed the identical methodology and described issues relevant only to the $\mathrm{C}-30$ data below. The global IGS stations have been used as GCPs in this study just like in Mukul Manas et al. (2015).

\subsection{Obtaining IGS GCPs}

A total of 427 stations exist in the IGS Network (Supplementary data) out of which only 335 stations were usable as some stations were out of the SRTM zone (latitude greater than $60^{\circ} \mathrm{N}$ and $57^{\circ} \mathrm{S}$ ).
The statistical analysis, therefore, was done with these 335 IGS GCPs (figure 1a). The C-90 study was carried out with 334 IGS GCPs (Mukul Manas et al. 2015).

\subsection{Obtaining $C$-Band $30 \mathrm{~m}$ resolution data}

The void-filled, C-30 data were available at the US Geological Survey website and were downloaded from the USGS Earth Explorer Interface in GeoTiff format. The GCPs were superimposed over these GeoTiff files in ArcGIS and the corresponding EGM96 (orthometric) heights of the $30 \mathrm{~m} \mathrm{C}$-Band SRTM points were extracted. Geoidal separations were added to the orthrometric heights to convert them to ellipsoidal heights for comparison with the ellipsoidal heights of the GCPs following the methodology outlined in Mukul Manas et al. (2015).

\subsection{Statistical analysis}

The C-30 heights were subtracted from the IGS GCP heights to obtain the error at each of the 335 IGS locations. The dataset was subjected to normality tests to compute the appropriate statistical measure (LE90 or RMSE) for comparison of results with other datasets. The stem-and-leaf method (figure 2) was used to identify outliers or locations with very high errors. For 48 out of the 335 GCPs, errors were between -1285 and $2306 \mathrm{~m}$; these were filtered as outliers (figure 1b). Bogota, Colombia, at elevation $2576.8 \mathrm{~m}$, had the highest error of $2305.9 \mathrm{~m}$. These outliers resulted from errors in measurement, collection or interpolation of data and caused inflation of errors (Zimmerman $1994,1995,1998)$. There were 20 outlier GCPs common to the 3 -arc C-Band $90 \mathrm{~m}$ resolution (C90), 1-arc C-Band $30 \mathrm{~m}$ resolution (C-30) and 1-arc $\mathrm{X}$-Band $30 \mathrm{~m}$ resolution (X-30) datasets (tables 1 and 2). The outliers were also analysed against the elevation of the IGS station and the errors were found to increase with station elevation (figure 3). On removal of the outliers the errors were uniformly distributed (figure 4).

The complete dataset (335 GCPs) and the outlier-filtered dataset (287 GCPs) were subjected to statistical analysis and mean error (ME), standard deviation (SD), standard error of mean (SEM), mean absolute error (MAE) and root mean square error (RMSE) were computed. The outlierfiltered dataset was separated into continents and the results were compared to the previously published results (Rodriguez et al. 2005, 2006; Mukul Manas et al. 2015). The main objective of doing the statistical analysis was to extend the Mukul Manas et al. (2015) analysis by comparing the results of the C-30 data to that from C-90 and X-30 data. 

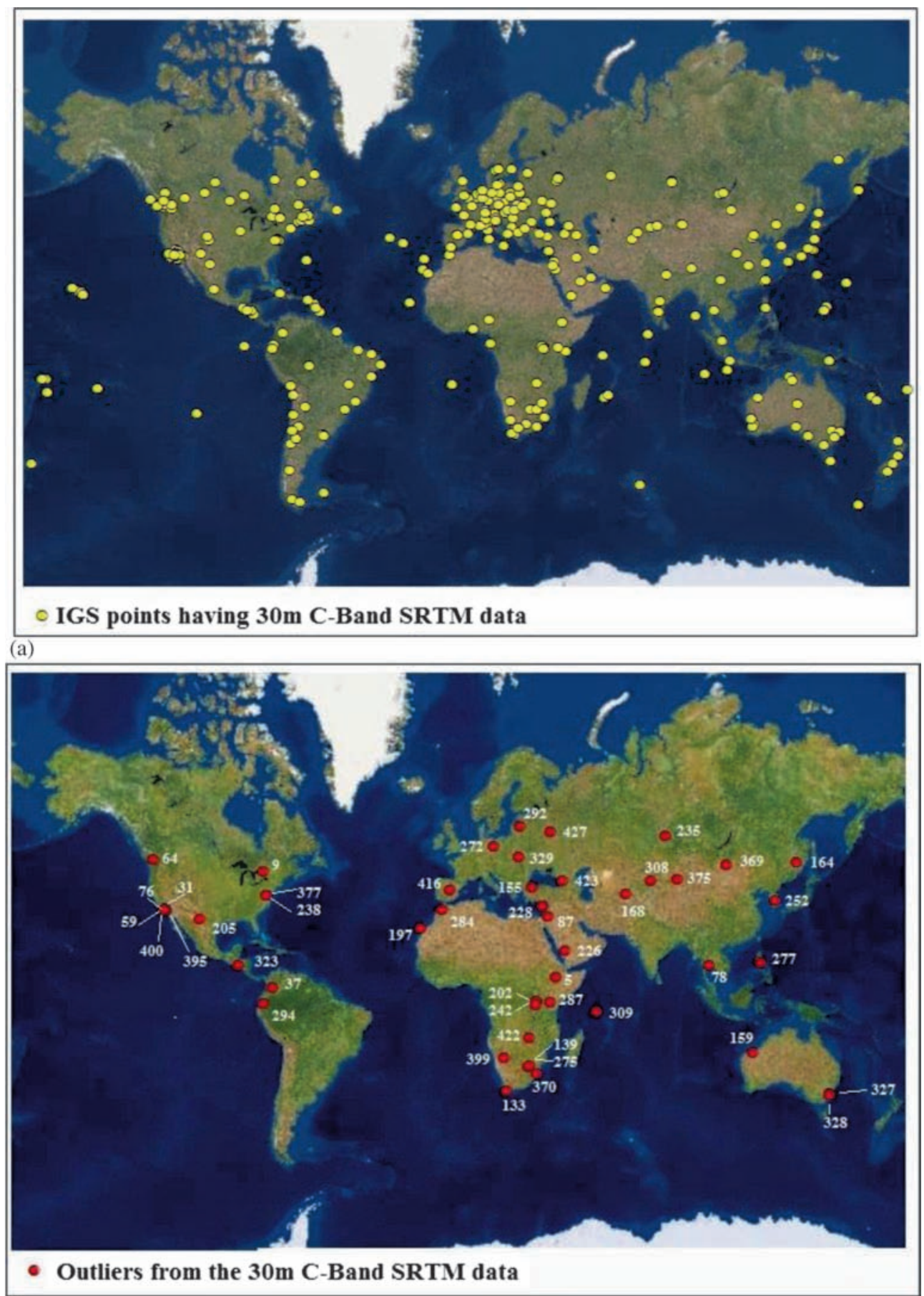

(b)

Figure 1. (a) Map showing the distribution of 335 IGS GCPs used to assess the vertical accuracy of the global 1-arc, $30 \mathrm{~m}$ resolution, C-Band SRTM dataset. (b) Map showing the distribution of 48 C-30 outliers with their corresponding station numbers.

\section{Results}

\subsection{The global $C$-Band $30 m$ dataset}

The statistical analysis for the C-30 global data was done with both the outlier-filtered and outlierincluded datasets consisting of 287 and 335 GCPs (table 2). The normality tests failed for both the datasets. The outlier-included data had skewness of
6.46 (standard error $=0.13$ ) and kurtosis of 89.17 (standard error $=0.27$ ) whereas the skewness and kurtosis of outlier-filtered data was 0.52 (standard error $=0.14$ ) and 0.84 (standard error $=0.29$ ) respectively. The Shapiro-Wilk's $(p>0.05)$ (Shapiro and Wilk 1965; Razali and Wah 2011) normality test also failed with $p=0.00$ for both the datasets. Therefore, as the C-30 dataset failed the normality test, the RMSE (and not LE90) is the appropriate 


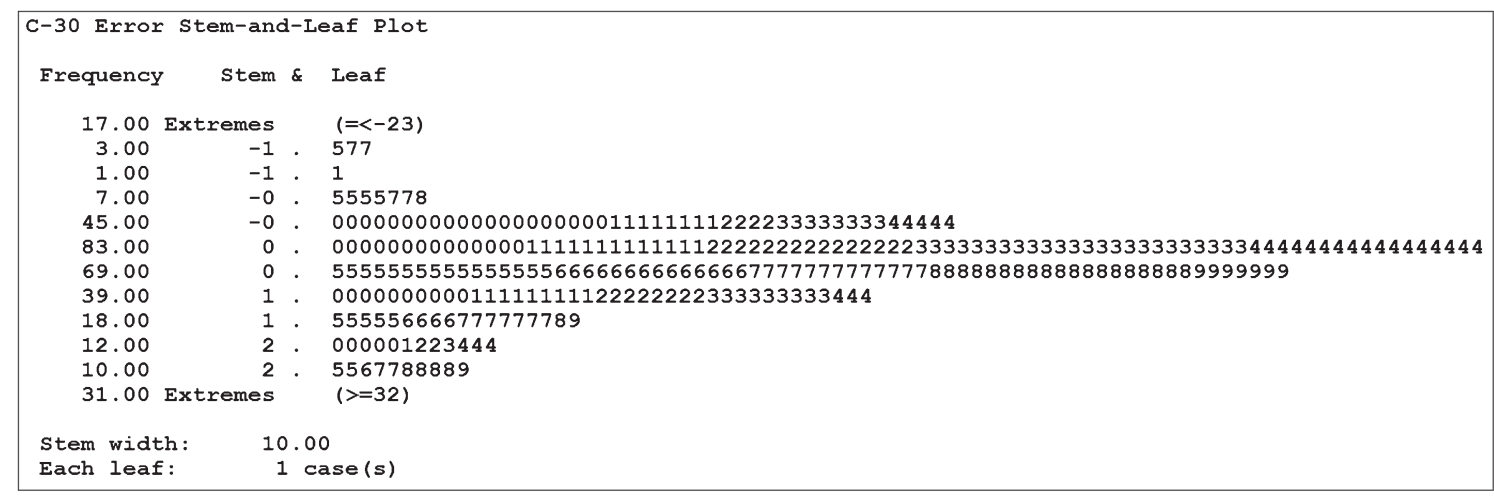

Figure 2. The Stem-and-Leaf plot indicating the presence of 48 C-Band 30m (C-30) outliers.

Table 1. Details of the outlier stations common to the C-90, C-30 and X-30 datasets.

\begin{tabular}{|c|c|c|c|c|c|c|c|}
\hline Sl. no. & $\begin{array}{c}\text { Station } \\
\text { no. }\end{array}$ & IGS station & Country & $\begin{array}{c}\text { IGS } \\
\text { elevation }(\mathrm{m})\end{array}$ & $\begin{array}{c}\text { C-90 } \\
\text { error }(m)\end{array}$ & $\begin{array}{c}\text { C-30 } \\
\text { error }(m)\end{array}$ & $\begin{array}{c}\mathrm{X}-30 \\
\text { error }(\mathrm{m})\end{array}$ \\
\hline 1 & 37 & Bogota & Colombia & 2576.8 & 2306.9 & 2305.9 & 2309.8 \\
\hline 2 & 59 & San Gabriel Mountains & USA & 1567.5 & 529.0 & 545.0 & 534.5 \\
\hline 3 & 64 & Chilliwack & Canada & 170.0 & 150.1 & 149.1 & 148.0 \\
\hline 4 & 78 & Patumwan & Thailand & 76.1 & 93.6 & 87.6 & 75.1 \\
\hline 5 & 87 & Metzoki dragot & Israel & 120.3 & 96.9 & 95.9 & 101.3 \\
\hline 6 & 159 & Karratha & Australia & 109.2 & 45.4 & 45.4 & 47.2 \\
\hline 7 & 164 & Khabarovsk & Russia & 130.6 & 80.1 & 80.1 & 81.6 \\
\hline 8 & 235 & Novosibirsk & Russia & 150.0 & 44.7 & 44.7 & 45.0 \\
\hline 9 & 242 & Kigali & Ruanda & 1485.3 & 91.0 & 57.4 & 108.3 \\
\hline 10 & 252 & Osan & South Korea & 48.9 & -25.9 & -25.9 & -24.1 \\
\hline 11 & 277 & Taguig City & Philippines & 86.6 & -160.2 & -155.2 & -150.4 \\
\hline 12 & 292 & Riga & Latvia & 34.7 & -25.9 & -26.9 & -33.3 \\
\hline 13 & 308 & Almaty & Kazakstan & 1340.0 & -635.2 & -635.2 & -651.0 \\
\hline 14 & 323 & San Salvador & El Salvador & 664.4 & 43.2 & 43.2 & 43.4 \\
\hline 15 & 329 & Lviv & Ukraine & 370.5 & 82.4 & 80.4 & 80.5 \\
\hline 16 & 369 & Ulaanbataar & Mongolia & 1611.7 & 51.9 & 51.9 & 62.7 \\
\hline 17 & 377 & Washington & USA & 48.9 & -174.7 & -174.7 & -183.1 \\
\hline 18 & 395 & Whittier & USA & 94.3 & 85.7 & 85.7 & 90.3 \\
\hline 19 & 400 & Mt. Wilson & USA & 1705.3 & 1492.1 & 1492.1 & 1493.3 \\
\hline 20 & 427 & Zwenigorod & Russia & 272.0 & 78.7 & 79.7 & 74.0 \\
\hline
\end{tabular}

statistical measure to ascertain compliance of SRTM data accuracy with SRTM goal.

The ME of the outlier-included global dataset was $20.4 \mathrm{~m}$ with SEM of $10.2 \mathrm{~m}$ indicating a positive bias (table 2). The SD of the dataset was $185.7 \mathrm{~m}$. The MAE and the RMSE were 40.7 and $186.5 \mathrm{~m}$ respectively. The RMSE was $\sim 19$ times higher than the SRTM goal of RMSE $\sim 10 \mathrm{~m}$. The errors reduced significantly after the 48 outliers were filtered. The ME reduced to $6.5 \mathrm{~m}$ with SEM of $0.5 \mathrm{~m}$. The plot of outlier filtered errors (figure 5) also indicate a positive bias. The SD of the outlier filtered dataset reduced to $8.1 \mathrm{~m}$. Both the MAE and RMSE were significantly lower at 7.8 and $10.3 \mathrm{~m}$. The RMSE at $10.3 \mathrm{~m}$ was close to the SRTM RMSE goal of $\sim 10 \mathrm{~m}$.

\subsection{Dataset consisting of stations with coincident C-30, C-90 and X-30 data}

Statistical analysis of 155 GCPs (table 3) with coincident C-30, C-90 and X-30 outlier-included data indicated a positive bias of $\sim 34 \mathrm{~m}$ in the $\mathrm{ME}$ for all the three datasets. The MAE was $\sim 49 \mathrm{~m}$, SD $\sim 231 \mathrm{~m}, \mathrm{SEM} \sim 19 \mathrm{~m}$ and RMSE $\sim 233 \mathrm{~m}$ for all the datasets. When the outliers were filtered from 


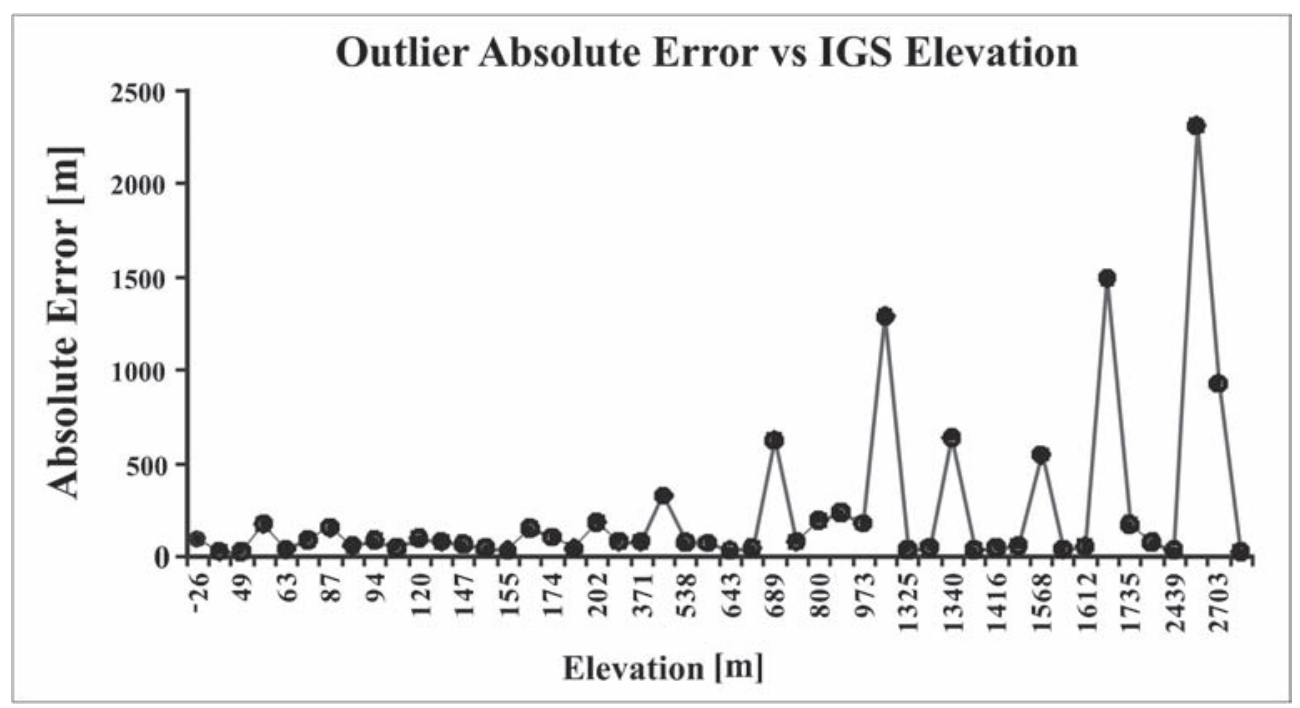

Figure 3. Plot of C-Band $30 \mathrm{~m}$ absolute error magnitude with increasing IGS elevation for the outliers.

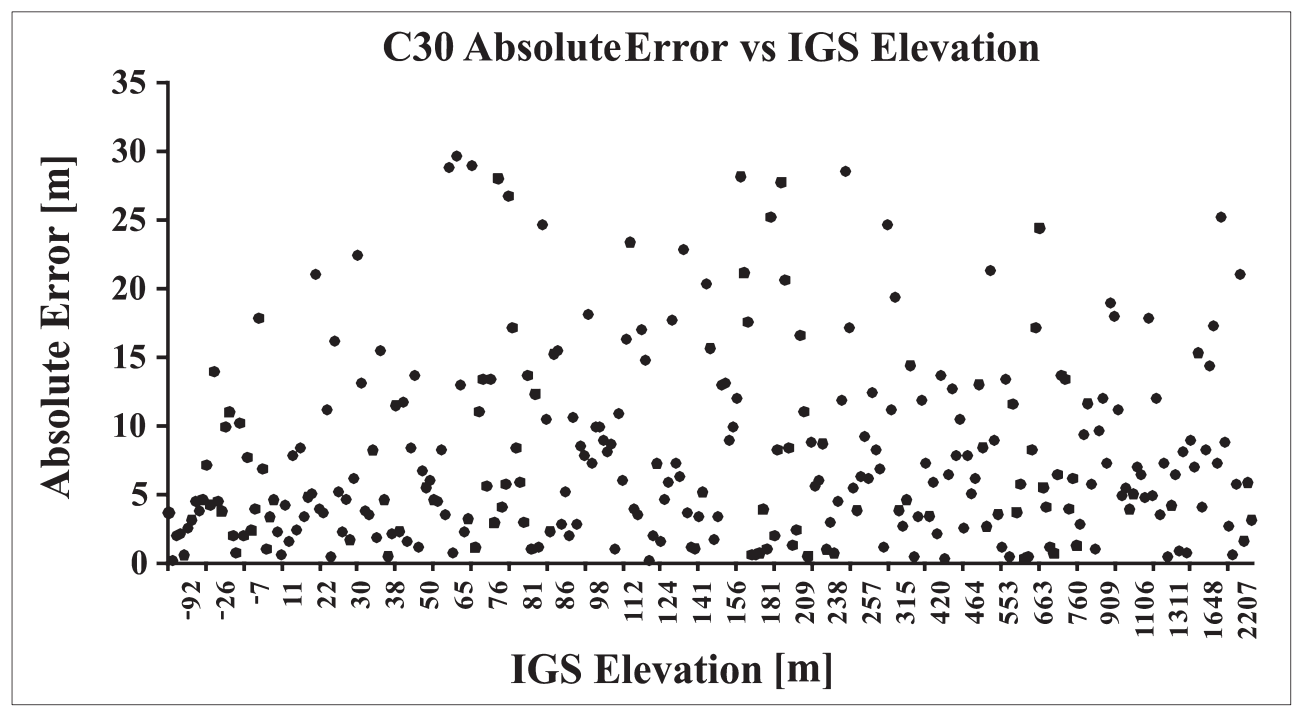

Figure 4. Plot showing C-Band $30 \mathrm{~m}$ outlier-filtered absolute errors with increasing elevation of the IGS stations. Outliers and errors are higher at higher elevations.

Table 2. Results of the statistical analysis of global SRTM data for both the outlier-included and outlier-filtered datasets.

\begin{tabular}{|c|c|c|c|c|c|c|}
\hline \multirow[b]{2}{*}{ Datasets } & \multicolumn{3}{|c|}{ Outlier-included } & \multicolumn{3}{|c|}{ Outlier-filtered } \\
\hline & $\overline{\mathrm{C}-90}$ & $\mathrm{C}-30$ & $\overline{\mathrm{X}-30}$ & $\overline{\mathrm{C}-90}$ & $\mathrm{C}-30$ & $\mathrm{X}-30$ \\
\hline Total stations considered & 334 & 335 & 156 & 290 & 287 & 135 \\
\hline Mean error $(\mathrm{ME})[\mathrm{m}]$ & 32 & 20.4 & 34.2 & 6.9 & 6.5 & 8.2 \\
\hline Mean absolute error (MAE) $[\mathrm{m}]$ & 51 & 40.7 & 48.4 & 7.8 & 7.8 & 8.8 \\
\hline Root mean square error (RMSE) $[\mathrm{m}]$ & 274.5 & 186.5 & 232.6 & 10.3 & 10.3 & 11.5 \\
\hline Standard deviation (SD) $[\mathrm{m}]$ & 273.5 & 185.7 & 230.8 & 7.8 & 8.1 & 8.1 \\
\hline Standard error (SEM) $[\mathrm{m}]$ & 15 & 10.2 & 18.5 & 0.5 & 0.5 & 0.7 \\
\hline Total number of outlier stations & 44 & 48 & 21 & - & - & - \\
\hline
\end{tabular}

all the datasets, the ME and MAE of the three datasets improved to $\sim 8$ and $\sim 9 \mathrm{~m}$, respectively. The RMSE for the three datasets were $\sim 11.5 \mathrm{~m}$. The SD and SE were $\sim 9$ and $0.8 \mathrm{~m}$ respectively.

\subsection{Continental dataset}

In order to compare the C-30 outlier-filtered results with earlier global studies (Rodriguez et al. 2005; 


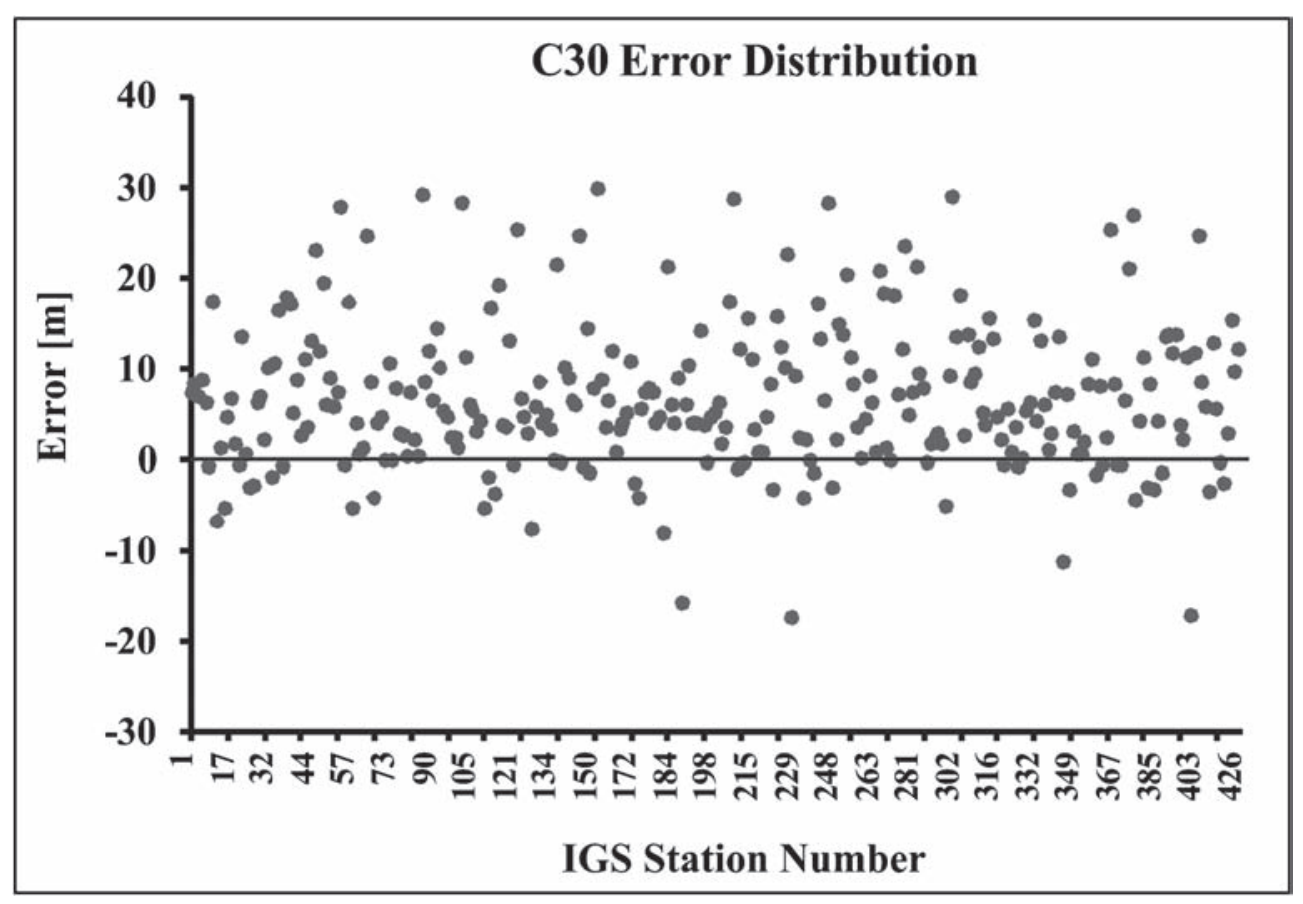

Figure 5. Plot showing a positive bias for the outlier filtered C-Band 30m errors for all the IGS stations.

Table 3. Results of the coincident C-90, C-30 and X-30 data.

\begin{tabular}{|c|c|c|c|c|c|c|}
\hline \multirow{2}{*}{$\begin{array}{l}\text { Common GCPs } \\
\text { Datasets }\end{array}$} & \multicolumn{3}{|c|}{ Outlier-included } & \multicolumn{3}{|c|}{ Outlier-filtered } \\
\hline & $\mathrm{C}-90$ & $\mathrm{C}-30$ & $\mathrm{X}-30$ & $\overline{\mathrm{C}-90}$ & $\mathrm{C}-30$ & $\mathrm{X}-30$ \\
\hline No. of points & 155 & 155 & 155 & 131 & 133 & 134 \\
\hline Mean error $[\mathrm{m}]$ & 34.5 & 34.0 & 34.4 & 8.0 & 7.7 & 8.2 \\
\hline Mean absolute error (MAE) $[\mathrm{m}]$ & 48.9 & 48.7 & 48.7 & 8.8 & 9.1 & 8.9 \\
\hline Standard deviation (SD) $[\mathrm{m}]$ & 230.9 & 231.0 & 231.5 & 8.3 & 8.9 & 8.1 \\
\hline Standard error (SEM) [m] & 18.6 & 18.6 & 18.6 & 0.7 & 0.8 & 0.7 \\
\hline Root mean square error (RMSE) [m] & 232.7 & 232.8 & 233.3 & 11.5 & 11.7 & 11.5 \\
\hline
\end{tabular}

Mukul Manas et al. 2015), the global dataset was separated into continents (Supplementary data). The continent-wise results for the C-30 data are shown in table 4 . The ME of the continents ranged from 3 (Australia) to $8.5 \mathrm{~m}$ (Asia). The SD for all the continents were between 4.5 and $10 \mathrm{~m}$, with the lowest value of $4.6 \mathrm{~m}$ from the Island dataset and highest $9.8 \mathrm{~m}$ from Africa. The SEM ranged from 0.7 (Eurasia) to $2.6 \mathrm{~m}$ (Africa). The MAE of the continents ranged between 3.5 (Australia) and $9.4 \mathrm{~m}$ (Europe and Asia).

The RMSE of Asia $(12.1 \mathrm{~m})$, Europe $(11.9 \mathrm{~m})$ and Africa $(10.3 \mathrm{~m})$ were marginally higher than the SRTM RMSE goal of $\sim 10 \mathrm{~m}$. Australia, N. America, S. America and the Island dataset complied with the SRTM goal with RMSEs of 5.9, 8.7, 9.7 and $5.7 \mathrm{~m}$, respectively. Eurasia, consisting of a combined dataset of 139 GCPs from Asia and Europe, returned a ME of $8.4 \mathrm{~m}$, SD of $8.6 \mathrm{~m}$ and SEM of $0.7 \mathrm{~m}$. The MAE and RMSE of Eurasia were 9.4 and $12 \mathrm{~m}$, respectively.

\section{Discussion}

The Global SRTM DTED are being used without considering errors, outliers or any accuracy estimation (Wechsler 2003). Our analysis of C-30 (tables 1 and 2) as well as C-90 and X-30 (Mukul Manas et al. 2015) data have pointed to significant errors and presence of outliers in all the SRTM datasets. The largest outliers for C-90 and X-30 were obtained at Mauna Kea, USA (3687 m) and Bogota, Colombia (2309.8 m) respectively. Bogota, Colombia $(2305.9 \mathrm{~m})$ is also the largest outlier for C-30. Such large outliers increase the RMSE for SRTM data by an order of magnitude over the SRTM goal of RMSE $\sim 10 \mathrm{~m}$. For example, outlier-included data for the C-30 dataset has a RMSE of $\sim 187 \mathrm{~m}$ for global data which is lower than that of the C-90 $(274.5 \mathrm{~m})$ and X-30 $(232.6 \mathrm{~m})$ datasets (table 2$)$. This is further supported by the C-90, C-30 and X-30 RMSEs of $\sim 233 \mathrm{~m}$ respectively computed from GCPs with coincident X- and C-Band data (table 3). Most 
of the high errors were from the high elevation regions (figure 3 ). Therefore, as the vertical accuracies of all the outlier-included datasets are an order of magnitude higher than the SRTM goal, it is inaccurate to use raw SRTM datasets, particularly in higher elevations, as they will give statistically insignificant results. Removal of outliers before use of all SRTM data is absolutely essential to get the SRTM datasets close to the SRTM RMSE goal of $\sim 10 \mathrm{~m}$ as well as for statistically meaningful results. This is evident from the analysis of the global dataset (table 2) where outlier-filtered C-30, C-90 and X-30 dataset have RMSE $\sim 10-11.5 \mathrm{~m}$. Also, GCPs with coincident X-30, C-30 and C-90 datasets have RMSE of $\sim 11.5 \mathrm{~m}$ (table 3 ). It is also evident that C-Band data have lower RMSE of $10.3 \mathrm{~m}$ than that of X-30 data (RMSE $11.5 \mathrm{~m}$ ) for the global dataset.

The results of the C-30 dataset were also compared with the C-90 and X-30 datasets after separating the global dataset into continental datasets (Rodriguez et al. 2005, 2006; Mukul Manas et al. 2015) (table 4). The RMSEs of C-30 data for Africa, Asia, Eurasia and the Island dataset were higher than the RMSEs of C-90 data. The X-30 RMSE was lower than C-30 and C-90 RMSEs in Africa and North America (table 4). The C-30 data RMSEs were lower than that for C-90 and X-30 data for Australia, Europe and S. America. For Asia, Eurasia and the Islands, the RMSEs for C-30 data were lower than that of the X-30 data but higher than the C-90 data. The difference between the RMSE of $\mathrm{C}$-Band $30 \mathrm{~m}$ and $\mathrm{X}$-Band $30 \mathrm{~m}$ were in the range between 1.0 and $2.5 \mathrm{~m}$ for Australia, Europe, Asia, N. America and S. America. The highest variation $(3.3 \mathrm{~m})$ of the RMSE was in Africa (table 4). The C-30 RMSE results, however, were much higher than the Rodriguez et al.'s (2005) RMSE results (table 5). The RMSE of all the continents of the Rodriguez et al. (2005) study complied with the SRTM goal with values in the range between 3.4 and $5.5 \mathrm{~m}$. However, only Australia, N. America, $\mathrm{S}$. America and the Island dataset complied with the SRTM goal of RMSE $\sim 10 \mathrm{~m}$ for the C-30 data (tables 4 and 5).

The mean errors for all the SRTM data were positive, indicating a bias which could be corrected to improve the vertical accuracy of the SRTM heights. A single pixel of $90 \mathrm{~m}$ resolution has the same elevation (x) (figure 6) for a region covering $8100 \mathrm{~m}^{2}$, where as a single pixel of $30 \mathrm{~m}$ resolution has the same elevation for a region of $900 \mathrm{~m}^{2}$. Hence, the C-30 data should be more accurate as nine different elevation values $(\mathrm{x} 1, \mathrm{x} 2, \ldots, \mathrm{x} 9)$ are available (figure 6) in C-30 for a single C-90 pixel for the same $8100 \mathrm{~m}^{2}$. The RMSEs of C-30 global data are seen to be within SRTM RMSE goal only for the Australian, Island and N. and S. American continents. 
Table 5. Comparison of RMSEs of C-Band $30 \mathrm{~m}$ resolution data with C-Band $90 \mathrm{~m}$ data from Mukul Manas et al. (2015) and Rodriguez et al. (2005) and X-Band $30 \mathrm{~m}$ SRTM from Mukul Manas et al.'s (2015) study.

\begin{tabular}{|c|c|c|c|c|c|}
\hline \multirow{2}{*}{$\frac{\text { Datasets }}{\text { Global }}$} & \multicolumn{2}{|c|}{ Rodriguez et al. (2006) } & \multirow{2}{*}{$\frac{\frac{\mathrm{C}-\text { Band } 90 \mathrm{~m}}{\mathrm{RMSE}(\mathrm{m})}}{10.3}$} & \multirow{2}{*}{$\frac{\frac{\mathrm{X}-\mathrm{Band} 30 \mathrm{~m}}{\mathrm{RMSE}(\mathrm{m})}}{11.5}$} & \multirow{2}{*}{$\frac{\frac{\mathrm{C}-\mathrm{Band} 30 \mathrm{~m}}{\mathrm{RMSE}(\mathrm{m})}}{10.3}$} \\
\hline & LE90 (m) & Computed RMSE (m) & & & \\
\hline Africa & 5.6 & 3.4 & 7.9 & 7 & 10.3 \\
\hline Australia & 6 & 3.7 & 6.9 & 7.6 & 5.9 \\
\hline Asia & - & - & 11 & 14.2 & 12.1 \\
\hline Europe & - & - & 12.4 & 13.4 & 11.9 \\
\hline Eurasia & 6.2 & 3.8 & 11.9 & 13.8 & 12.0 \\
\hline Islands & 8 & 4.9 & 5 & 6.1 & 5.7 \\
\hline N. America & 9 & 5.5 & 9 & 7.3 & 8.7 \\
\hline S. America & 6.2 & 3.8 & 11.2 & 11.5 & 9.7 \\
\hline
\end{tabular}
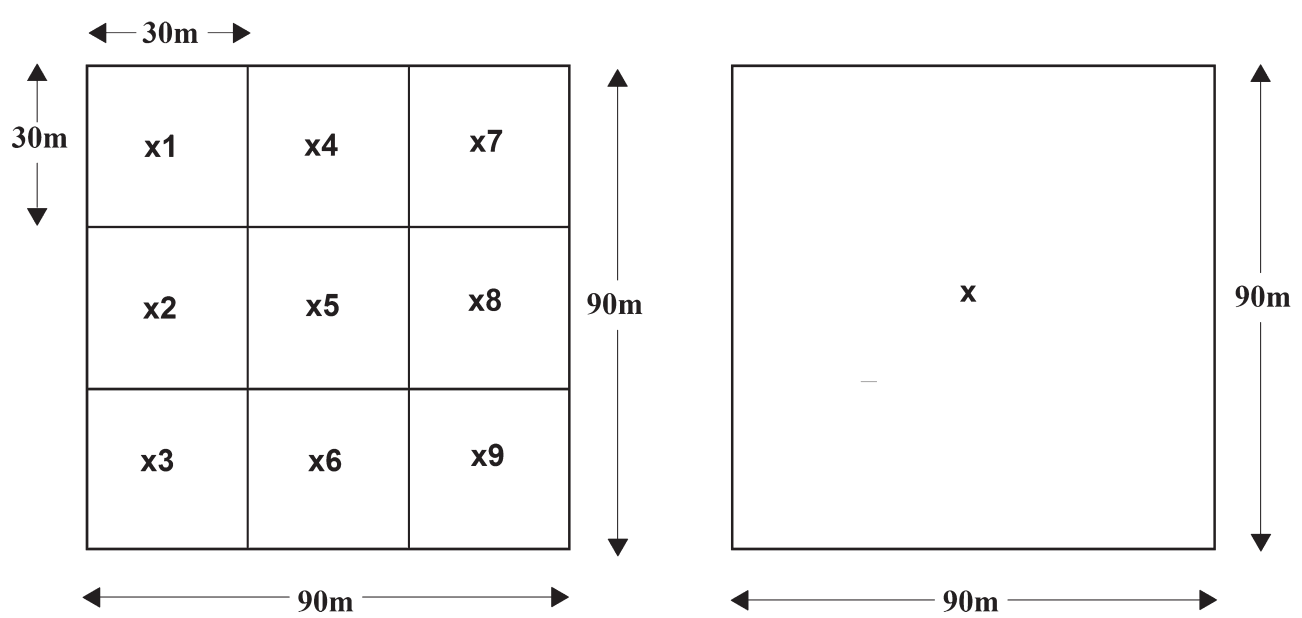

Figure 6. Diagram indicating the differences between the pixels belonging to $90 \mathrm{~m}$ and $30 \mathrm{~m}$ resolution SRTM data. A single pixel from a $90 \mathrm{~m}$ resolution data has a single elevation value, indicated by ' $\mathrm{x}$ ' whereas for the same area, the $30 \mathrm{~m}$ offers 9 pixel with separate elevation values indicated by 'x1, x2, x3, .., x9'.

Therefore, accuracy analysis of SRTM data with denser GCPs (e.g., Rodriguez et al. 2005) but with better spatial distribution (e.g., Mukul Manas et al. 2015) is required to assess the differences in the quality of C-90, X-30 and C-30 SRTM data in continents better. Meanwhile, our present work along with Mukul Manas et al. (2015) clearly demonstrates the severe problems associated with using raw SRTM data without the removal of outliers and analysis of errors.

\section{Conclusions}

1. A global assessment of the recently released 1-arc, $30 \mathrm{~m}$ resolution, C-Band SRTM dataset using the GCPs from the global IGS Network (table 5) reveals that it has the same accuracy and RMSE $(10.3 \mathrm{~m})$ as the 3 -arc, $90 \mathrm{~m}$ resolution $\mathrm{C}-$ Band data. However, it is more accurate than the $30 \mathrm{~m}$ resolution, X-Band $(11.5 \mathrm{~m})$ SRTM data. The RMSEs of all the datasets are marginally higher than the SRTM RMSE goal of $\sim 10 \mathrm{~m}$.
2. Accuracy analysis of STRM data from GCPs with coincident C-30, C-90 and X-30 data (table 3) indicate that outlier-filtering reduces the RMSEs of the datasets from $\sim 233$ to $\sim 11.5 \mathrm{~m}$. The accuracies of the three datasets are almost identical. Also the errors in the C-30 increase with the increase in elevation.

3 . When the global dataset is divided into continents, only the 1-arc, $30 \mathrm{~m}$ resolution, C-Band SRTM dataset from Australia, N. America, S. America and the Island dataset comply with the SRTM RMSE goal of $\sim 10 \mathrm{~m}$ (table 4 ). The RMSEs of Australia, Europe, N. America and S. America for C-30 data are lower than the RMSEs of C-90 data whereas for Africa, Asia and the Island dataset the C-Band $90 \mathrm{~m}$ data has higher accuracy. Except Africa and N. America, the RMSEs of C-30 $\mathrm{m}$ data are lower than the X-Band $30 \mathrm{~m}$ data for all other datasets.

4. All SRTM products have outliers corresponding to high errors between the GCP and the SRTM heights especially at high elevations. Therefore, raw SRTM products cannot be used without 
assessing their uncertainties and removal of outliers. The mean errors of all SRTM datasets are positive for the global as well as continental datasets and hence correction of the positive bias can improve the accuracy of the SRTM dataset.

\section{Acknowledgements}

This is an IITBESCDL/001/2015 publication. The work was funded by the Ministry of Earth Sciences India, Grant No. MoES/16/01/09-RDEAS and Department of Science and Technology India, Grant No. SR/S4/ES-415/2009 to Malay. VS acknowledges IITB for the Teaching Assistantship in the Department of Earth Sciences. Critical reviews by two anonymous reviewers and comments of the JESS handling editor helped to significantly improve the quality of this paper. We are grateful to the editorial staff of JESS for painstakingly putting this paper together. We benefited from discussions with Sridevi Jade, D Ramakrishnan and Rishikesh Bharti.

\section{References}

Bamler R 1999 The SRTM mission: A world-wide $30 \mathrm{~m}$ resolution DEM from SAR interferometry in 11 days; In: Photogrammetric Week (eds) R Fritsch and R Spiller, pp. $145-154$.

Dow J M, Neilan R E and Rizos C 2009 The International GNSS Service in a changing landscape of Global Navigation Satellite; J. Geodesy 83(3-4) 191-198.

Farr T G and Kobrick M 2000 Shuttle radar topography mission produces a wealth of data; Trans. Am. Geophys. Union 81 583-585.

Farr T G, Rosen P A, Caro E, Crippen R, Duren R, Hensley S, Kobrick M, Paller M, Rodriguez E, Roth L, Seal D, Shaffer S, Shimada J, Umland J, Werner M, Oskin M, Burbank M and Alsdorf D 2007 The Shuttle Radar Topography Mission; Rev. Geophys. 45 RG2004, doi: 10.1029/2005RG000183.

JPL Shuttle Radar Topography Mission 2009 Technical Fact Sheet; http://www2.jpl.nasa.gov/srtm/index.html.
Kolecka N and Kozak J 2014 Assessment of the accuracy of SRTM C- and X-Band high mountain elevation data: A case study of the Polish Tatra Mountains; Pure Appl. Geophys., doi: 10.1007/s00024-013-0695-5.

Mouratidis A, Briole P and Katsambalos K 2010 SRTM 300 DEM (versions 1, 2, 3, 4) validation by means of extensive kinematic GPS measurements: A case study from North Greece; Int. J. Remote Sens. 31(23) 6205-6222.

Mukul Manas, Srivastava V and Mukul Malay 2015 Analysis of the accuracy of Shuttle Radar Topography Mission (SRTM) height models using International Global Navigation Satellite System Service (IGS) Network; J. Earth Syst. Sci. 124(6) 1343-1357.

Rabus B, Eineder M, Am Roth and Bamler R 2004 The shuttle radar topography mission - a new class of digital elevation models acquired by space borne radar; J. Photogramm. Remote Sens. 57 241-262.

Razali N M and Wah Y B 2011 Power comparisons of Shapiro-Wilk, Kolmogorov-Smirnov, Lilliefors and Anderson-Darling test; J. Stat. Model. Anal. 2(1) 21-33.

Rodriguez E, Morris C S and Belz J E 2006 A global assessment of the SRTM performance; Photogramm. Eng. Remote Sens. 72 249-260.

Rodriguez E, Morris C S, Belz J E, Chapin E C, Martin J M and Daffer W 2005 An assessment of the SRTM topographic products; Technical Report JPLD-31639 Pasadena California: Jet Propulsion Laboratory, 143p.

Shapiro S S and Wilk M B 1965 An analysis of variance test for normality (complete samples); Biometrika 52(3/4) 591-611.

USGS 2005 Shuttle radar topography mission; http://srtm. usgs.gov.

Varga M and Tomisla B 2015 Accuracy validation and comparison of global digital elevation models over Croatia; Int. J. Remote Sens. 36(1) 170-189.

Wechsler S P 2003 Perceptions of digital elevation model uncertainty by DEM users; URISA-WASHINGTON DC 15(2) $57-64$.

Werner M 2001 Shuttle radar topography mission (SRTM), mission overview; J. Telecommun. (Frequenz) 55 75-79.

Zimmerman D W 1994 A note on the influence of outliers on parametric and nonparametric tests; J. General Psychology 121(4) 391-401.

Zimmerman D W 1995 Increasing the power of nonparametric tests by detecting and downweighting outliers; $J$. Experimental Education 64(1) 71-78.

Zimmerman D W 1998 Invalidation of parametric and nonparametric statistical tests by concurrent violation of two assumptions; J. Experimental Education 67(1) 55-68.

MS received 10 September 2015; revised 11 March 2016; accepted 4 May 2016

Corresponding editor: Pradeep Kumar Thapliyal 